\title{
A PROSPECTIVE STUDY TO EVALUATE THE FUNCTIONAL OUTCOIME OF NON- INSTRUMENTED LUMBAR DECOIMPRERSSION IN ADULT DEGENERATIVE LUMBAR CANAL STENOSIS [LCS] AND DETERIMINE PREDICTIVE FACTORS OF FAVOURABLE OUTCOME.
}

KEY WORDS: Lumbar canal stenosis, VAS, decompression.
Dr Rakesh Prasad

MBBS, DNB Orthopedic Surgery JIMS Hospital, Nishchintapur, Kolkata, West Bengal, 700137

\section{Dr Sunny N}

\section{Prasad*}

\section{MBBS, DNB Orthopedic Surgery. *Corresponding Author}

AIM AND OBJECTIVES: A prospective study to evaluate the functional outcome of non- instrumented lumbar decompression in adult degenerative lumbar canal stenosis [LCS] and determine predictive factors of favourable outcome.

Study details: Patients attending Orthopedic OPD at BARC Hospital, Mumbai, who were operated for adult degerative LCS from June 2017 to May 2019.

CONCLUSION: The VAS and Beaujon score were stasistically significant when compared to preoperative and 3 months post operatively.

\section{INTRODUCTION}

Lumbar canal stenosis (LCS) is commonly seen in the elderly especially owing to the aging of the spine with prevalence ranging from $1.7 \%-13.1 \%(1-3)$ Growing in the facet joints, ligamentum flavum hypertrophy, disc degeneration, and osteophytes cause the spinal canal to constrict and accordingly result in spinal cord and nerve root compression. (4) The dynamics affect the foramen with flexion causing a $12 \%$ increase, and extension a $15 \%$ decrease, in surface area.(5) Chief symptoms are low back pain and leg pain worsened by walking and numbness in the legs (6). Although numerous studies have been published, controversy still exists regarding the indication of surgical treatment(7-8). Growing information of the patho-anatomy, joined with highresolution imaging, has permitted a detailed localization of nerve root compression, which generally happens near the intervertebral space and the expanded ligamentum of flavum (9-11).The prime indication for surgery being non responsive to conservative management and severe canal stenosis noncompliant to conservative management.

Surgery for spinal stenosis consists of either decompression alone, or decompression with spinal fusion. Decompression by laminectomy is the treatment of choice for central or lateral recess stenosis. On the other hand, fusion is required if foraminal stenosis is present. Whenever possible, the source of pain should be localized with selective root blocks preoperatively, to allow a more focal decompression. A good approach is to start the decompression at a point of lesser stenosis and work towards the area of most severe stenosis. It is desirable to attain decompression with minimally invasive techniques, and preserving the paraspinal muscle, spinous processes, supraspinous and interspinous ligaments [9]. A microscope or magnifying loupes and tubular retractor system are helpful [10]

Fusion is required if there is excessive facetectomy, as more than $50 \%$ compromises stability [8], or if stenosis is combined with isthmic or degenerative spondylolisthesis [12], scoliosis, kyphosis or synovial facet joint cyst. Other indications for fusion include adjacent segment degeneration after prior fusion, and recurrent stenosis or herniated disc after decompressed site [9]. If fusion is likely, the hips should remain extended to prevent positional kyphosis.

The lack of consensus and worldwide variability exists in making a surgical decision for patients with lumbar stenosis. During the last decade studies with high evidence have been published and reported that the majority of the patients benefit from surgery both in reducing pain and improving function, faster and in larger extent than the conservative management. (13-15). Recently several prospective studies |www.worldwidejournals.com reported functional benefit in $60 \%$ to $79 \%$ of cases following decompression surgery $(16,17,18)$. However, the addition of instrumentation and an arthrodesis to decompression has disadvantages: increased surgical costs, complications, a higher rate of local infection, and increased surgical time and blood loss. [5,7] Decompression alone has been described as an alternative and effective procedure for older patients and those without hypermobility on dynamic lumbar spine radiographs. $[2,8,12]$ In this context, identifying a subgroup of patients who may benefit from an isolated decompression would be an important improvement in the management of patients with DS.

Hence, we decided to conduct a prospective study to evaluate the functional outcome of non-instrumented lumbar decompression in adult degenerative Lumbar Canal Stenosis (LCS) patients admitted to a tertiary care centre.

\section{AIMS \& OBJECTIVES:}

AIIM:

To analyze functional outcome of Non-instrumented lumbar decompression in adult degenerating LCS and determine predictive factors of favorable outcome.

\section{OBJECTIVES:}

i. To evaluate preoperative functional status of the patients using following scores:

a. VAS score

b. Beaujon Score

ii. To evaluate postoperative functional status of the patients using same scores at the end of 3 months

iii. To compare improvement in functional status of the patient before and after surgery.

\section{MATERIALS \& METHODS}

Study Area- Patients attending Orthopedic OPD at BARC Hospital, Anushakti nagar, Mumbai.

Study Population- Patients with Clinico-radiologically confirmed adult cases of LCS under the Contributary health service scheme (CHSS) of the department of atomic energy (DAE). These includes employee of BARC and allied units and their family members.

\section{Eligibility Criteria:}

\section{INCLUSION CRITERIA-}

i. Only Clinico-radiologically confirmed adult cases of degenerative LCS presenting at Orthopedic OPD at BARC Hospital.

\section{EXCLUSION CRITERIA-}

i. Congenital spinal canal stenosis 
ii. Pediatric spinal canal stenosis

iii. Patient with known psychiatric disorder or taking antipsychotic drugs who cannot comply with the outcome measurement.

iv. Lumbar spine trauma or tumors

v. Co-morbities hampering patients surgical fitness

vi. Associated pathology responsible for functional disability (cervical myelopathy, peripheral neuropathy, cerebro-vascular accident, peripheral arterial disease stage 2-4 according to the Leriche and Fontaine, inflammatory rheumatoid disease).

vii. Patient with spinal stability

\section{Study Design-}

Prospective study involved a series of consecutive patients who were operated for adult degenerative LCS. The goal was to analyse the functional outcome at 3 months and determine predictive factors of favourable outcome.

\section{Study duration-From June 2017 to May 2019}

\section{Study intervention-}

Patients were placed in prone position in the operation room. Under image intensifier guidance, level of operative spinous process were localized. Patients were prepped and draped. The median incision was centered on the spinous processes. Laminotomy with or without Laminectomy and with or without inter-transverse fusion and with or without fusion of facet joints at offending levels were performed. Concomitant discectomy was performed in patients with associated herniated disc. Decompression of the central spinal canal, lateral spinal canal and nerve root foramen was performed. Average time of surgery was variable from 40 minutes to 90 minutes and the average intra-operative blood loss was $150 \mathrm{ml}$ to $700 \mathrm{ml}$ depending upon number of levels of decompression.

\section{Methods of Measurement of Outcome of Interest-}

i. VAS score

ii. Beaujon score

Figure: Beaujon Score:

\begin{tabular}{|c|c|c|c|c|c|c|}
\hline ticemipoints & 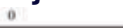 & 1 & 2 & 3 & 4 & Tox \\
\hline Wula ing dituance & $<100 \mathrm{~m}$ & $100-900 \mathrm{~m}$ & $>500 \mathrm{~m}$ & Untimined & - & 3 \\
\hline Reting les pain & Contant & Major crives: & Mad and tare crives & Abremt & - & \\
\hline Ambulatory leg pain & Upon first steps & Rare and late & Absent & & - & 2 \\
\hline Back pain & Constant & Major crives & Mis and fate crives & Aberent & & \\
\hline Nemontogic defikit & Majoer & - & Mis & - & Atsent & \\
\hline Paintiller we & $\begin{array}{l}\text { Stroeng medication } \\
\text { required }\end{array}$ & $\begin{array}{l}\text { Mild medication } \\
\text { if cockanional une }\end{array}$ & No medicititas oue & - & - & 2 \\
\hline Quality of life & Pont & Fair & Good & Exseflent & $=$ & 3 \\
\hline
\end{tabular}

Sample Size-30

\section{Sample Size(N)=(Z)2.P.(1-P)/e2}

Sample size for finite population $(\mathrm{n})=\mathrm{N} /[1+(\mathrm{N}-1) / \mathrm{m}]$

where ' $\mathrm{N}$ ' is the sample size for infinite population

' $n$ ' is the sample size for finite population

' $\mathrm{m}$ ' is the beneficiary population of BARC Hospital taken as 86000

' $\mathrm{Z}$ ' is the confidence interval taken as $95 \%$ hence the value is 1.96

' $\mathrm{P}$ ' is the prevalence obtained from previous studies which is $1.7 \%$ to $13.1 \%(\operatorname{avg} 9.3 \%)$

' $\mathrm{e}$ ' is the maximum effort tolerance error for the prevalence taken as 0.1

Hence, the sample size calculated falls in the range of $2-44$ (around 30)

\section{DATA COLLECTION METHOD-}

A total of 30 clinico-radiologically confirmed patients were recruited in this prospective study from June 2017 to May 2019 after fulfilling inclusion and exclusion criteria.

$$
\square
$$

Pre-operative evaluation of the patient using VAS score and Beaujon score

Posterior lumbar decompression with non-instrumented posterior lumbar fusion was performed in these selected patients
At the end of 3 months patients were evaluated using VAS score and Beaujon Score

\section{Statistical Method:}

Patients were assessed pre-operatively and post-operatively 3 months after the surgery using Visual analogue score (VAS) and Beaujon score. Those parameters were compared in the affected side between the immediate post-operative and 3 months after surgery with the students paired t test.

All statistical processes were conducted using the Statistical Package for the Social Sciences (SPSS) v 23 and $p$ values of $<0.05$ was considered as significant.

\section{RESULTS:}

Over a 2 years duration we recruited $n=33$ patients in our study and all patients were followed after 3 months postoperatively.

Table 1: Age-wise Distribution of Cases:

\begin{tabular}{|c|c|c|}
\hline Age Group: & No. of Cases: & Percentage: \\
\hline$<40$ years & 8 & $24.2 \%$ \\
\hline $41-50$ years & 5 & $15.2 \%$ \\
\hline $51-60$ years & 10 & $30.3 \%$ \\
\hline$>60$ years & 10 & $30.3 \%$ \\
\hline
\end{tabular}

\section{Figure 1: Sex-wise Distribution of Cases:}

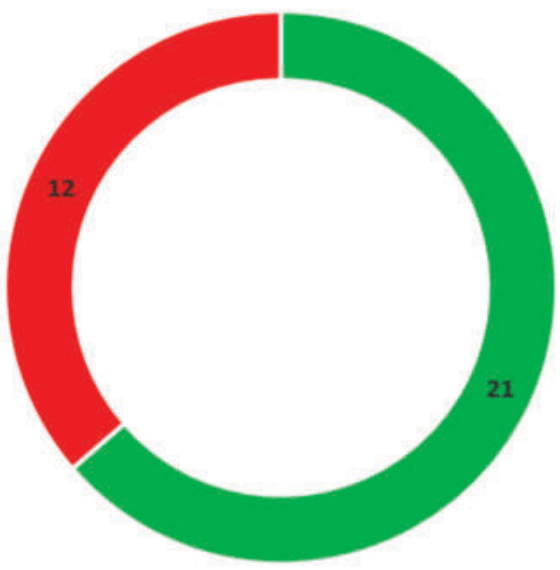

- Males - Females

Table 2: Distribution of Co-Morbidities amongst cases:

\begin{tabular}{|c|c|c|}
\hline Co-Morbidities: & No. of Cases: & Percentage: \\
\hline Hypertension & 7 & $21.2 \%$ \\
\hline Diabetes Mellitus & 7 & $21.2 \%$ \\
\hline Asthma & 3 & $9.1 \%$ \\
\hline
\end{tabular}

$\mathrm{n}=13$ cases in our study had L4-L5 level pathological involvement of the spine.

Table 3: Distribution as per Spinal Level of Pathology:

\begin{tabular}{|c|c|c|}
\hline Spinal Pathology: & No. of Cases: & Percentage: \\
\hline Single Level & 18 & $54.5 \%$ \\
\hline Multiple Level & 15 & $45.6 \%$ \\
\hline
\end{tabular}

Table 4: Distribution as per type of surgical procedure performed:

\begin{tabular}{|c|c|c|}
\hline Surgical Procedure: & No. of Cases: & Percentage: \\
\hline Decompression & 22 & $66.7 \%$ \\
\hline Laminectomy & 7 & $21.2 \%$ \\
\hline Microdiscectomy & 4 & $12.1 \%$ \\
\hline \multicolumn{2}{|c|}{ |www.worldwidejournals.com } \\
\hline
\end{tabular}


Table 5: VAS Scores compared Pre \& 3 months PostOperatively:

\begin{tabular}{|c|c|c|c|}
\hline VAS Scores: & Mean \pm SD: & Median [Range]: & p value: \\
\hline Pre-Operative Score & $7.3 \pm 1.2$ & $7[5,9]$ & $<0.0001$ \\
\hline 3 Months Post & $2.5 \pm 1.1$ & $3[1,4]$ & \\
Operative Score & & & \\
\hline
\end{tabular}

The pre-operative and post-operative VAS Scores have been compared in the above data. Wilcoxon matched pair rank test has been applied \& $\mathrm{p}<0.05$ was to be considered significant. Since $\mathrm{p}<0.0001$ the 3 months post-operative VAS score in all our paired patients is statistically significant when compared to their pre-operative scores.

Table 6: Beaujon Scores compared Pre \& 3 months PostOperatively:

\begin{tabular}{|c|c|c|c|}
\hline VAS Scores: & Mean \pm SD: & Median [Range] & p value: \\
\hline Pre-Operative Score & $8.5 \pm 2.7$ & $9[4,14]$ & $<0.0001$ \\
\hline $\begin{array}{l}3 \text { Months Post- } \\
\text { Operative Score }\end{array}$ & $16.8 \pm 2.4$ & $17[9,20]$ & \\
\hline
\end{tabular}

The pre-operative and post-operative Beaujon Scores have been compared in the above data. Wilcoxon matched pair rank test has been applied \& $p<0.05$ was to be considered significant. Since $p<0.0001$ the 3 months post-operative Beaujon score in all our paired patients is statistically significant when compared to their pre-operative scores.

\section{Table 7: Distribution of post-operative complications:}

\begin{tabular}{|c|c|c|}
\hline Post-Operative Complications & No. of Cases: & Percentage: \\
\hline Infection & 2 & $6.1 \%$ \\
\hline CSF Leak & 1 & $3.1 \%$ \\
\hline Recurrence & 1 & $3.1 \%$ \\
\hline
\end{tabular}

\section{DISCUSSION:}

There are very few studies that evaluated the surgical results of performing a lumbar decompression with fusion but without additional instrumentation in patients with grade I and II DS and spinal stenosis. A total of 130 patients with DS were treated with $\mathrm{DF}$ without instrumentation using different surgical techniques. [14,15]

Pateder and Benzell3 performed a retrospective study of 62 patients to evaluate the radiographic and clinical efficacy of uninstrumented facet fusion in elderly patients with singlelevel DS and spinal stenosis. The surgical technique used by the authors consisted of removal of the spinous process and then standard laminectomies and foraminotomies, preserving the pars interarticularis bilaterally. The authors then identified the plane of the facet joints, performing a capsulotomy, in line with the dorsal facet joint. With an $8 \mathrm{~mm}$ burr hole they removed bone from the facet joints (about 5 $\mathrm{mm}$ deep), incorporating both walls of the dorsal joint followed by packing local autograft in this space. A lumbar corset was prescribed during ambulation for 2 months. Patients were divided into 2 groups: group 1 included 39 patients with no translation on dynamic radiographs at the listhetic segment ( $<2 \mathrm{~mm}$ translation), whereas group 2 (23 patients) was defined by the presence of translation at the listhetic segment on dynamic radiographs (>2 mm). In group 2,16 were classified as grade I DS and 7 were grade II. Postoperatively, in group I, $36 \%$ of the index listhetic facet fusion levels had >2-r15 mm of motion (14/ 39 levels had increased translation at the index level). In patients with $>2$ but $\mathrm{r} 5 \mathrm{~mm}$ of postoperative motion, 10 of 11 patients were "much better." Fifty percent of patients with $>5-\mathrm{r} 10 \mathrm{~mm}$ of motion and no patients with $>10-\mathrm{r} 15 \mathrm{~mm}$ of motion were better after surgery. This suggests that the extent of postoperative motion was inversely correlated with patientderived outcomes. In group 2 there were similar trends: 9 of 16 (56\%) patients had $\mathrm{r} 2 \mathrm{~mm}$ motion at the last follow-up, 3 of 16 demonstrated $>2$ and $\mathrm{r} 5 \mathrm{~mm}$ of motion, $3 \mathrm{had}>5$ and $\mathrm{r} 10 \mathrm{~mm}$, and $1 \mathrm{had}>10-\mathrm{r} 15 \mathrm{~mm}$ of motion at final follow-up. In the 7 patients with a preoperative dynamic grade II DS, the average preoperative motion at the index listhetic level was $7.1 \mathrm{~mm}$. Three of these 7 index listhetic levels attained $r 2 \mathrm{~mm}$ of motion on the postoperative flexion/extension radiographs. Two index listhetic levels had $>2-\mathrm{r} 5 \mathrm{~mm}$ of postoperative motion, while one level had >5-r $10 \mathrm{~mm}$ of motion and another level had $>10-r 15 \mathrm{~mm}$ of motion. Also in group 2, all 3 patients with r2 mm of motion reported that they were "much better" after surgery. However, only $50 \%$ of those with $>2-\mathrm{r} 5 \mathrm{~mm}$ of postoperative motion were much better and none of the patients with $>5-\mathrm{r} 10 \mathrm{~mm}$ or $>10-\mathrm{r} 15 \mathrm{~mm}$ were "much better." The overall improved outcome was higher in group 1 (fixed spondylolisthesis) than in group 2, as was the postoperative radiographic stabilization rate. As final conclusions, for patients who underwent a laminectomy for a grade I or II fixed or mobile DS, concomitant facet fusion decreases motion and stabilizes the spine. This suggests that in patients with preoperative dynamic instability, uninstrumented facet fusion can eliminate motion or reduce motion. Increased postoperative motion was associated with a worse clinical outcome after surgery, whereas better clinical outcomes correlated with less motion on postoperative dynamic radiographs. Level III evidence-retrospective cohort study. McCulloch performed a retrospective review of 21 patients who had decompression with fusion without instrumentation for spinal stenosis with DS.[19] The fusion was uninstrumented and was performed between the transverse processes with autograft iliac crest bone. The mean follow-up was 38 months after surgery and patients were assessed using 4 scores: (1) their overall satisfaction with the outcome of surgery, (2) an analog back and leg pain scale, (3) a functional evaluation scale, and (4) Ferguson (upshot) anteriorposterior lumbosacral and lateral flexion-extension radiographs. After evaluation, the overall outcome on all 4 scales was considered satisfactory in $16(76 \%)$ of the cases and 20 patients had clinical improvement of their claudicant leg pain. The fusion rate was $86 \%$ (18 cases). Among the 3 patients with a pseudoarthrosis, 2 had a good clinical outcome and 1 did not. One patient with a stable fusion complained of back pain, whereas another had persistent leg pain. The overall satisfactory outcome based on nonradiographic scale was 18 of 21 . The authors concluded that a decompression with posterolateral fusion without instrumentation can be a reasonable option to treat symptomatic stenosis associated with DS. Level IV evidence-retrospective case series.

Kornblum et al performed a prospective study on patients who underwent posterior lumbar decompression with bilateral posterolateral arthrodesis using autogenous bone graft in patients with DS and spinal stenosis.[20] A total of 47 patients with single-level lumbar spinal stenosis with spondylolisthesis were treated. Patients had a radiographic evaluation to determine fusion status and were also assessed clinically with a validated self-administered spinal stenosis questionnaire. Radiographs were taken at final clinical followup to evaluate fusion (range from 2 to $4 \mathrm{y}$ ). There were 22 patients $(47 \%)$ with a solid fusion. The clinical outcome was correlated with the presence of successful fusion, whereas preoperative back and lower limb pain were statistically similar between the 2 groups. The mean follow-up was 7 years 8 months. The clinical outcome was excellent or good in $86 \%$ of patients with a solid fusion and in $56 \%$ of patients with pseudoarthrosis $(P=0.01)$. Preoperatively, spondylolisthesis measured $6.4 \mathrm{~mm}$ in the solid fusion group and $6.9 \mathrm{~mm}$ in the pseudoarthrosis groups, ranging from 2 to $18 \mathrm{~mm}$. Preoperative sagittal motion averaged $3 \mathrm{~mm}$ for both groups, ranging from 0 to $11 \mathrm{~mm}$. After surgery, the spondylolisthesis averaged $7.3 \mathrm{~mm}$ and sagittal motion decreased to $2.6 \mathrm{~mm}$ in the pseudarthrosis group. The amount of spondylolisthesis remained the same for the solid fusion group, whereas sagittal motion decreased to $1.0 \mathrm{~mm}$. The solid fusion group performed significantly better in the symptom severity and physical function categories on the self-administered questionnaire. Although both groups had similar results in the patient satisfaction category of the questionnaire, the presence of solid fusion improved the long-term clinical results compared with pseudoarthrosis. Level II evidence-prospective comparative study. 


\section{REFERENCES:}

1. Holm S. Pathophysiology of disc degeneration. Acta Orthop Scand Suppl. 1993;251:13-15. [PubMed] [Google Scholar]

2. Rauschning W. Pathoanatomy of lumbar disc degeneration and stenosis. Acta Orthop Scand Suppl. 1993;251:3-12. [PubMed] [Google Scholar]

3. Rauschning W. Normal and pathologic anatomy of the lumbar root canals. Spine (Phila Pa 1976) 1987;12:1008-1019. [PubMed] [Google Scholar]

4. Arnoldi CC, Brodsky AE, Cauchoix J, et al. Lumbar spinal stenosis and nerve root entrapment syndromes. Definition and classification. Clin Orthop Relat Res. 1976;(115):4-5. [PubMed] [Google Scholar]

5. Yoshida M, Shima K, Taniguchi Y, Tamaki T, Tanaka T. Hypertrophied ligamentum flavum in lumbar spinal canal stenosis. Pathogenesis and morphologic and immunohistochemical observation. Spine (Phila Pa 1976) 1992;17:1353-1360. [PubMed] [Google Scholar]

6. Lee CK, Rauschning W, Glenn W. Lateral lumbar spinal canal stenosis: classification, pathologic anatomy and surgical decompression. Spine (Phila Pa 1976) 1988;13:313-320. [PubMed] [Google Scholar]

7. Kirkaldy-Willis WH,Wedge JH, et al. Lumbar spinal nerve lateral entrapment. Clin Orthop Relat Res. 1982;(169): 17 1-178. [PubMed] [Google Scholar]

8. Kunogi J, Hasue M. Diagnosis and operative treatment of intraforaminal and extraforaminal nerve root compression. Spine (Phila Pa 1976) 1991;16:1312-1320. [PubMed] [Google Scholar]

9. Vanderlinden RG. Subarticular entrapment of the dorsal root ganglion as a cause of sciatic pain. Spine (Phila Pa 1976) 1984;9:19-22. [PubMed] [Google Scholar]

10. Jenis LG, An HS. Spine update: lumbar foraminal stenosis. Spine (Phila Pa 1976) 2000;25:389-394. [PubMed] [Google Scholar]

11. Hasegawa T, Mikawa Y, Watanabe R, An HS. Morphometric analysis of the lumbosacral nerve roots and dorsal root ganglia by magnetic resonance imaging. Spine (Phila Pa 1976) 1996;21:1005-1009. [PubMed] [Google Scholar]

12. Porter RW, Hibbert C, Evans C. The natural history of root entrapment syndrome. Spine (Phila Pa 1976) 1984;9:4 18-421. [PubMed] [Google Scholar]

13. Kikuchi S, Sato K, Konno S, Hasue M. Anatomic and radiographic study of dorsal root ganglia. Spine (Phila Pa 1976) 1994;19:6-11. [PubMed] [Google Scholar]

14. Hasegawa T, An HS, Haughton VM, Nowicki BH. Lumbar foraminal stenosis: critical heights of the intervertebral discs and foramina: a cryomicrotome study in cadavera. J Bone Joint Surg Am. 1995;77:32-38. [PubMed] [Google Scholar]

15. Wiltse LL, Guyer RD, Spencer CW, Glenn WV, Porter IS. Alar transverse process impingement of the L5 spinal nerve: the far-out syndrome. Spine (Phila Pa 1976) 1984:9:31-41. [PubMed] [Google Scholar]

16. Rydevik B, Brown MD, Lundborg G. Pathoanatomy and pathophysiology of nerve root compression. Spine (Phila Pa 1976) 1984;9:7-15. [PubMed] [Google Scholar]

17. Schonstrom N, Hansson T. Pressure changes following constriction of the cauda equina: an experimental study in situ. Spine (Phila Pa 1976) 1988;13:385-388. [PubMed] [Google Scholar]

18. Paine KW. Clinical features of lumbar spinal stenosis. Clin Orthop Relat Res. 1976;(115):77-82. [PubMed] [Google Scholar]

19. Mc Culloch Laminoplasty vs traditional decompression: How far can you reach? Raphael Lotan, MDYigal Bronstein, MD AlbertYee, MD Joel Finkelstein, Doi:http://doi.org/10.1016/j.spinee.2008.06.048

20. Kornblum MB, Fischgrund JS, Herkowitz HN, Abraham DA, Berkower DL, Ditkoff JS. Degenerative lumbar spondylolisthesis with spinal stenosis: a prospective long term study comparing fusion and pseudarthrosis. Spine 2004;2:726-33; discussion 33-4 